\title{
LOS DOS COPISTAS DEL MANUSCRITO DE SMARAGDO (JOHN RYLANDS LIBRARY, MS. LAT. 104)
}

\author{
POR \\ PALOMA CUENCA MuÑOZ \\ Universidad Complutense de Madrid \\ palomacm@ghis.ucm.es
}

\begin{abstract}
RESUMEN
La obra de Smaragdo titulada Expositio in Regulam Sancti Benedicti se ha conservado en varios códices copiados en escritura visigótica. De ellos, el manuscrito conservado en la John Rylands Library con la signatura Ms. Lat. 104 contiene una serie de peculiaridades que, desde el punto de vista paleográfico, hacen de especial interés su estudio, sobre todo en lo referente a los copistas que intervienen en la escritura del texto.

PALABRAS CLAVES: Paleografía, Escritura visigótica. Codicología, Smaragdo, Regla de San Benito.

\section{THE TWO COPISTS FROM THE MANUSCRIPT OF SMARAGDUS (JOHN RYLANDS LIBRARY, MS. LAT. 104)}

\begin{abstract}
Expositio in Regulam Sancti Benedicti is a plate from Smaragdus that is conserved in various codices which are copied into Visigothic book-writing. From these ones the only manuscript conserved is found in the John Rylands Library with the signature of Ms. Lat. 104 containing a series of peculiarities that from the point of view of a palaeographical make especial interest in his study, especially in the referent to the copists which appear in the text.
\end{abstract}

KEY WORDS: Palaeography, Visigothic hand-writing, Codicology, Smaragdus, Rule of Saint Benedict.

$\begin{array}{ll}\text { Recibido/Received } & 23-07-2014 \\ \text { Aceptado/Accepted } & 02-09-2014\end{array}$

\section{SMARAGDO Y SU OBRA}

Aunque no sea el propósito de las siguientes consideraciones realizar un estudio histórico detallado, sino paleográfico, sobre la transmisión textual de la Expositio in Regulam Sancti Benedicti, es necesario introducir algunas puntualizaciones sobre el contexto biográfico y monacal de su autor. Smaragdo, de origen godo, nace hacia el año 770 en el suroeste de la Galia. ${ }^{1}$ Parece muy probable su pertenencia como abad, al menos, a dos monasterios de la zona de Verdún en el noreste de la Galia, así como su labor de visitador enviado por el rey Luis el Piadoso a los famosos sínodos de Aquisgrán en los años 816 y 817, ya que en sus

1 Las notas biográficas están tomadas de la Introducción de la edición crítica de A. Spannagel y P. Engelbert de la obra de Smaragdo, 1974. Expositio in Regulam S. Benedicti: XXII-XXIX Siegburg (Alemania): Franz Schmitt; entre otros trabajos, como los de Ponesse, Matthew D. 2006. "Smaragdus of St. Mihiel and the Carolingian Monastic Reform". Revue Bénédictine 116: 367-392.
Comentarios, redactados poco después, hace mención a los decretos establecidos en dichas reuniones, lo que hace pensar también en una relación directa con el propio Benito de Aniano. A partir del año 824 decide cambiar la abadía de Castellio por la de Saint-Mihiel, seguramente por su mejor ubicación y accesibilidad.

Su producción escrita no se reduce a la obra que contiene los comentarios a la regla benedictina, de hecho el resto de su producción también posee un marcado carácter religioso con la intención de dotar a los monasterios de los instrumentos necesarios para la lectura y correcta interpretación de los textos sagrados (epístolas y evangelios), como es el caso del Liber scintillarum y la Expositio libri comitis (año 812). Además de su declarado interés por establecer una nueva regulación de la vida monástica según la propuesta de San Benito, también se ocupó de cuestiones de ámbito político (Via regia en el año 809 y la Diadema monachorum del año 817) y filológico (Liber in partibus Donati o In octo partibus oraciones, de la primera década del siglo 
IX. ${ }^{2}$ Dichas obras comparten con las de ámbito religioso, una finalidad propagandística y didáctica que subyace como elemento común de toda su producción escrita.

En conjunto, sus obras están pensadas para difundir ideas religiosas, políticas y culturales, intentando llegar al mayor número de receptores posibles. Con ello consigue aunar los nuevos contenidos, en el formato de una lengua latina evolucionada, con las fuentes clásicas (rito romano) sin despegarse del todo de la tradición anterior, a través del uso de las continuas citas a san Isidoro y a san Fructuoso, que pudo predisponer de modo más receptivo a las comunidades monacales hispanas más conservadoras a las que iba dirigido el mensaje en última instancia. ${ }^{3}$ Una vez mencionada su ingente labor divulgadora, hay que destacar la importancia de la Expositio in Regulam sancti Bendeciti, redactada a principios del siglo IX, especialmente en el ámbito hispánico por ser la única regla monástica copiada en la Península Ibérica durante la alta Edad Media posvisigótica. ${ }^{4}$

\section{LA EXPOSITIO IN REGULAM S. BENEDICTI}

El comentario de la Regla de San Benito constituye la obra más importante y más densa de las escritas por Smaragdo. Su contribución a la espiritualidad monástica a través de su obra se extendió durante toda la Edad Media y principio de la Edad Moderna, sobre todo en el ámbito cisterciense y en el desarrollo del uso de la regla benedictina, con respecto a la trascendencia que adquiere la espiritualidad dentro de la reforma carolina. ${ }^{5}$ Así, las reformas cistercienses del siglo XII

2 Un resumen de la producción de Smaragdo puede consultarse en Cuenca, P. 2009. "Un fragmento de un códice visigótico en la Biblioteca Nacional (ms. 18672)" en J.C. Galende y J. de Santiago (dirs.), VIII Jornadas Científicas sobre documentación de la Hispania altomedieval (ss. VI-X): 80-83, Madrid: Departamento de Ciencias y Técnicas Historiográficas/Universidad Complutense de Madrid. La enumeración completa de dichas obras puede consultarse en la traducción de D. Barry de Smaragdo. 2007. Commentary on the Rule of Saint Benedict: 10-11 Kalamazoo: Cistercian Publications.

3 Ángel Canellas López explica cómo esta mezcla entre la innovación benedictina y la tradición visigoda supuso un primer paso de aceptación que, seguramente, después se tuvo que ver completado con obras de marcado carácter hispánico como la de Salvo, abad de Abelda (Libellus a regula santi Benedicti subtractus), donde se mezcla la regla benedictina, a través de la visión de Smaragdo, con elementos castizos hispánicos (Canellas, A. 1980. "Los escritorios benedictinos". Cuadernos de historia Jerónimo Zurita 37-38: 169-170). No obstante, no toda la crítica especializada está de acuerdo con esta interpretación de la obra de Smaragdo, así Linage Conde, A. 1976. "Un testimonio de la europeización riojana en el siglo x". Biblioteca Gonzalo de Berceo: 85-105 (www. vallenajerilla.com) escribe "La utilización por Smaragdus de los Padres visigóticos no explica esta predilección hispana por su obra [...] más probable parece atribuirle a su íntima conexión con la personalidad y la obra de san Benito de Aniano".

4 Linage Conde, A. 1976: 85. Para una consulta sobre los más de sesenta testimonios conservados de la Expositio (http//www.albrechtdiem.org/research/mmp/texts/Smaragdus-Expositio.htm), además del Repertorium Geschichtsquellen des deutschen Mittelalters (Bayerische Akademie der Wissenschaften) (http://www.geschichtsquellen.de/ repOpus_04304.html).

5 Sobre la espiritualidad del texto de Smaragdo puede verse los trabajos de Leclercq, J. 1957 (reed. 1982), The Love of learning and the Desire for God: A study of Monastic Culture: 45-47 New York, Fordham University Press; y Leclercq, J. 1984. "Smaragdus", en P. E. Szurrmach (ed.), An Introduction to the Medieval Mystics of Europe: 37-39. Albany: State University of New York Press. se fundamentan en gran parte en las obras que Smaragdo escribiera en el siglo IX, sobre todo en la Expositio y en la Diadema Monachorum, según Leclercq, quien insiste en la duradera influencia que tienen ambos textos en la España de los siglos x y xI. Uno de los principales argumentos que justifican dicha afirmación consiste en el uso frecuente que se hizo de ambos en la Hispania medieval, como se atestigua por el gran número de copias conservadas de ambos manuscritos distribuidos por toda Europa, confirmando la Expositio como el manual de renovación monástica más utilizado, durante esta parte de la Edad Media. ${ }^{6}$

Los comentarios que Smaragdo realiza sobre la Regula Benedicti se plantean como un documento complementario y aclaratorio que, a través de un latín de estructuras gramaticales simples desprovisto de toda elocuencia y retórica, adapta para el uso de los monjes ordinarios la norma de San Benito explicando su aplicación de forma sencilla y ordenada. ${ }^{7}$ Las fuentes utilizadas son los textos más importantes y conocidos de la literatura religiosa en la época medieval, como es el caso de la Biblia y la Patrística. A todo ello se une una metodología que explica y aclara los conceptos mediante el uso de las acepciones etimológicas, incluso recurriendo con frecuencia al texto isidoriano.

La obra, que se publicó no sólo durante la Edad Media, sino también entre los siglos XVI al XIX ${ }^{8}$, se copió incluso en monasterios que no pertenecían a los tradicionales benedictinos, sino a órdenes de posterior aparición como Cartujos y Cistercienses, nacidas en el siglo XII. ${ }^{9}$ De todos los testimonios conservados, en el presente estudio tan sólo nos vamos a referir a los que de la Expositio se escribieron en la Península Ibérica durante la Edad Media, prestando una especial atención al análisis del testimonio de origen hispánico que se conserva en la actualidad en la John Rylands Library de Manchester, registrado con la signatura Ms.Lat.104.

\section{LOS TESTIMONIOS CONSERVADOS.}

El índice de testimonios conservados de la obra de Smaragdo puede consultarse en la base de datos Monastic Manuscript Project donde se recogen de la Expositio al menos 59 códices manuscritos, incluyendo textos completos y fragmentarios, cuya copia se extiende cronológicamente desde el siglo IX, momento de creación de la obra, hasta el siglo XVI. ${ }^{10} \mathrm{El}$ hecho de que este texto se reprodujera de

6 De la Expositio han sobrevivido al menos 59 testimonios y de la Diadema 120 manuscritos, casi todos de época medieval.

7 LaCorte, D. M. 2006. "Smaragdus of Saint-Mihiel: Ninth-Century Sources for Twelfth-Century Reformers". Cistercian Studies Quaterly, 41: 273-290; y la introducción de LaCorte, "The Expositio and monastic reform at Cîteaux", en la traducción de Smaragado, Barry D. 2007.

8 Las ediciones existentes conservadas que se realizaron en época moderna y contemporánea se pueden consultar en la edición de Spannengel y Engelbert de Smaragdo. 1974: XXI-XXII.

9 En la introducción de J. Leclercq "The relevante of Smaragdus to modern monasticism" a la traducción de Smaragdo. 2007: 26, realiza un rápido repaso de la tradición textual de la Expositio desde el siglo x al XIX.

10 Los datos que aporta dicha base de datos con respecto a Smaragdo de san Mihiel y en concreto a la Expositio in Regulam sancti Bendicti, pueden consultarse en la siguiente dirección (http://www. albrechtdiem.org/research/mmp/texts/Smaragdus-Expositio.html). 
forma manuscrita durante más de ocho siglos da la medida de la importancia que tuvo, como ya hemos señalado, en la formación y en el mantenimiento de la regla benedictina en los monasterios europeos durante toda la Edad Media y comienzos de la Edad Moderna. Se han conservado códices que contienen la Expositio o parte de ella en Francia, Inglaterra, Alemania, España, Portugal y Estados Unidos, y lejos de ir perdiendo vigencia según se alejaba el momento de su creación, se dio un resurgimiento, a tenor de los ejemplares conservados, que conllevaba un renovado interés por difundir la Regla a través del texto de Smaragdo durante el siglo Xv, época de la que se conservan trece copias, que es el mismo número de copias aproximado que se conservan del momento de mayor auge en los monasterios, el siglo XII. ${ }^{11}$

La crítica de los siglos XIX y XX comienza a centrar su atención en esta obra a raíz de los trabajos de Ludwig Traube y de la edición que incluye P. Migne en su Patrologia Latina (102, col.689B-932C). ${ }^{12}$ Sin embargo, no será hasta 1974 cuando A. Spannagel y P. Engelbert realicen una edición crítica definitiva, aplicando los parámetros que establece la crítica textual a los principales testimonios manuscritos para establecer una filiación entre todos ellos que aclara las variadas familias textuales en que se copiaron los diferentes testimonios, a la vez que establecen un completo catálogo que incluye la descripción básica de cada uno de los códices manuscritos conservados. El trabajo se realiza de forma excepcional tanto en la parte dedicada a la edición, donde se aplican criterios editoriales coherentes con respecto a la tipología del texto, como en lo que al estudio introductorio se refiere, donde los autores reúnen, ordenan y aclaran la variopinta información que hasta ese momento se había publicado sobre la Expositio, desterrando algunos errores repetidos por la crítica.

La obra de Smaragdo en la actualidad mantiene un elevado interés dentro del ámbito benedictino, como lo demuestran los recientes estudios, y sobre todo las traducciones que del texto original latino se han realizado a idiomas modernos como el inglés o el alemán. ${ }^{13}$

Dentro de la ingente cantidad de testimonios conservados, el presente trabajo se centra en primer término en los textos que originariamente pertenecen al ámbito hispánico, y que forman parte del importante acerbo de los códices visigóticos y carolinos, para finalmente focalizar nuestra atención en uno de los manuscritos más atractivo desde la óptica paleográfica, conservado en la biblioteca John Rylands, en Manchester.

11 Estos datos son aproximativos, ya que son numerosos los casos en que se duda de la datación del texto entre dos siglos; no obstante, y tomando en los casos de duda la fecha más antigua propuesta, los 59 testimonios registrados se distribuyen cronológicamente de la siguiente forma: diez del siglo IX, once del siglo X, dos del siglo XI, trece del siglo XII, cinco del siglo XIII, tres del siglo XIV, trece del siglo XV y dos del siglo XVI.

12 Desde finales del siglo XIX y durante la primera mitad del siglo $x x$, existe un nutrido grupo de investigadores que publican trabajos relacionados con la figura de Smaragdo, atraídos por la importancia que sus obras tienen para la orden benedictina, es el caso de I. Herwegen, J. Naberhaus, H. Frank, entre otros; pero, de todas esas publicaciones cabe destacar por su relevancia la de Traube, L. 1988. "Textgeschichte der Regula S. Benedicti, Bayerische Adademie der Wissenschaften München". Abhandlungen der Philosophisch (-philologischen)- historischen klasse 21/3:, 646-7 y 717-8.

${ }^{13}$ A ellas se refiere $\mathrm{D}$. Barry en la introducción a su traducción de Smaragado. 2007: 212

\section{LOS TESTIMONIOS DE TRADICIÓN HISPÁNICA}

Debido a la abundancia y dispersión en el espacio y en el tiempo de códices que contienen el comentario a la Regla benedictina, nos ha parecido interesante agrupar y describir, a partir de los datos recopilados por Spannagel y Engelbert en su imprescindible edición crítica de la Expositio de Smaragdo, los textos que pertenecen a la tradición hispana y que, por tanto, fueron copiados en escrituras visigótica y carolina según los modelos caligráficos de los diferentes monasterios en que se confeccionaron.

Los códices más antiguos son los copiados a finales del siglo IX. Uno se adscribe al monasterio de San Pedro de Cardeña, ${ }^{14}$ conservado en la John Rylands Library de Manchester (Mn) con la signatura Ms. Lat. 104 (116) y confeccionado en pergamino, le falta el inicio y el final del texto. Ocupa 185 folios de escritura visigótica, y desde el punto de vista paleográfico se vincula con uno de los testimonios del siglo x (London, B. M. Add. 30055), ya que ambos textos podrían compartir un origen común, Cardeña. El otro testimonio del siglo IX, es un códice completo conservado en la Biblioteca de la Real Academia de la Historia, Aemilian. 26, 139 folios (ff.5ra-144vb). Pergamino, 355mm. $\times 255 \mathrm{~mm} ., 2$ columnas. Realizado en el monasterio de San Millán. ${ }^{15}$

14 Con posterioridad se analiza el momento de composición de este códice, intentado acotar en lo posible la fecha.

15 Ruiz, E. 1997. Catálogo de la sección de Códices de la Real Academia de la Historia: 201-203 Madrid: Real Academia de la Historia, describe el testimonio fechado "s. IX ex." en la siguiente ficha codicológica: "Escritura visigótica pausada. Esporádicamente aparece una I alta con un copete peculiar. En general, figura la e caudada. A veces se encuentra la ligadura st en forma de puente. El uso del grupo tj ante vocal es irregular. La j tiene escaso desarrollo, salvo en un fragmento -al final de la columna del f. 176va - que presenta otra variedad gráfica. Aquí la j se emplea con regularidad y ofrece una forma muy desarrollada. Manos: A (ff. 5r-36v); B (36v-146r); C (147v-208v) y D (209r-211v). La mano $A$ presenta algunos rasgos de tipo mozárabe y alguna peculiaridad abreviativa. La mano B oscila en el uso de la abreviatura para autem (au / aum). La mano D abrevia dicha conjunción bajo la forma de au, y traza nexos de -at y de -as sobre todo en final de línea.

El pergamino es grueso y bien preparado. Tiene un color oscuro en lado del pelo. Los fascículos son cuaterniones, salvo el séptimo y el último. No hay signaturas ni reclamos. La foliación es moderna, a lápiz y en números arábigos.

Las dimensiones del folio y de la caja de escritura son respectivamente: $355 / 360 \times 2552 / 260 \mathrm{~mm}$. y $255 \times 180 \mathrm{~mm}$. La unidad de pautado es $10 \mathrm{~mm}$. El texto discurre a doble columna. La perforación consiste en incisiones horizontales en el centro del folio. Las modificaciones del pautado no coinciden con el cambio de mano. El número total de líneas verticales es: ff. 5-208: 4 (justificación: 4; marginales: 0); ff. 209-211: 8 (justificación: 4; marginales: 4). El número de líneas horizontales es: 25 (ff. 13-57 y 138-144); 26 (ff. 90-113 y 12); 29 (ff. 145-211). Líneas de escritura: 25 / 26 / 29.

Los títulos han sido trazados en capitales de corte epigráfico. Las rúbricas han sido trazadas en las mismas letras que el texto, pero en minio. Las iniciales primarias presentan adornos geométricos y cierta búsqueda formal. Los colores usados son verde, amarillo y minio. Las iniciales secundarias son sencillas, generalmente rellenas de algún color. Otros elementos ornamentales: f. 147r: Cruz de Oviedo con orla y dos personajes que tan sólo han sido abocetados (quizá han sido añadidos posteriormente); ff. 151v, 152v y 154v: Bebedores ataviados con turbantes y zaragüelles.

El ejemplar tal vez sea oriundo de un escriptorio navarro-pirenaico. Quizá tenga algún parentesco con el ms. 24, dado su parecido gráfico. Procede del monasterio de San Millán de la Cogolla. En un marbete que figura en el recto del f. inicial se lee: «La exposición de la Regla 
Del siglo $x$, se conservan seis testimonios de tradición hispana, entre los que cuales se cuenta sobre todo con fragmentos, además de algunas copias completas, tanto de origen castellano (Cardeña, Silos, San Millán y Nájera) como aragonés (San Benet de Bages):

1.- Fragmento. London, Bristish Museum Add. 30055. Folios $232 r$ a $237 v$. Pergamino, $260 \mathrm{~mm} . \times 170 \mathrm{~mm}$., 2 columnas. Este texto, junto con el manuscrito ya citado $\mathrm{Mn}$. son los únicos códices procedentes de Cardeña.

2.- Fragmento. Madrid, Archivo Histórico Nacional, Sección Clero, Carpeta 1030, número 24. Pergamino, caja de escritura $145 \mathrm{~mm} . \times 550 \mathrm{~mm}$. $(175 \mathrm{~mm} . \times 580 \mathrm{~mm}$.). Escritura visigótica.

3.- Varios fragmentos. Silos, Archivo del Monasterio, frag. 5-16. Pergamino, 340mm. $\times 235 \mathrm{~mm}$., 2 columnas. Llegó al monasterio de Santo Domingo de Silos en el siglo XVIII procedente del monasterio benedictino de Nájera. Escritura visigótica. ${ }^{16}$

4.- Incompleto, faltan fragmentos. Valvanera, (Vv) Archivo del Monasterio, s. n., 104 folios. Pergamino, $320 \mathrm{~mm} . \times 250 \mathrm{~mm}$., 2 columnas. Realizado después del año 954 según el colofón, en escritura visigótica. El origen de este códice es dudoso ya que se han apuntado dos posibles orígenes: el propio monasterio de Valvanera o el de San Millán de la Cogolla.

5.- Incompleto. Silos, Archivo del Monasterio 1 (S), 271 folios. Pergamino, $290 \mathrm{~mm} . \times 210 \mathrm{~mm}$., 1 columna. En los folios $179 r$ y 271 r existen sendos colofones donde aparece loannes notarius presbiter junto al año 945. Parece, por tanto, que el códice pudo estar copiado en dos momentos diferentes, así un escriba de finales del siglo IX copia los folios $1 r$ a $177 r$, mientras que los folios $177 v$ a $271 v$, habrían sido copiados por un escriba del siglo $x$, aunque ambos utilizan el mismo tipo de escritura, la visigótica.

6.- Fragmento. Montserrat, Biblioteca del Monasterio 793-I. Pergamino, 335mm ×225mm., 2 columnas. Realizado en San Benet de Bages (Manresa) es el único testimonio de este siglo que se copia en escritura minúscula carolina.

Del siglo XI, se conserva un único testimonio fragmentario de tradición hispana. Se trata de los folios $268 \mathrm{r}$ a $275 \mathrm{v}$ del manuscrito 18672 (99) conservado en la Biblioteca

de San Benito = Una homilía de San Chrisóstomo $=$ Y la obra de Paulo Albaro Cordobés». En el margen derecho de ese mismo folio figura una anotación más temprana que dice: "Expossición muy antigua sobre la regla de San Benito y sobre las scrituras de Santos Padres. Es la expossición de Smaragdo y al folio 148 el libro Scintilla Scripturarum. Parece ser el que anda con nombre de Albaro cordubense [///] la edición [///] de los padres toledanos tomo 2 fol. 418».

El códice está incompleto. La encuadernación, de tipo exento y en piel blanquilla, es moderna (a. 1961).

Signaturas antiguas: F 196 y 13".

16 En el estudio crítico de Spannagel y Engelbert a su edición de Smaragdo. 1974: XVII y XIX, se plantea la posibilidad de que los fragmentos 2 y 3 en realidad pertenecieran en origen a un mismo códice, puesto que ambos poseen características similares y comparten Nájera como lugar de copia.
Nacional de España, y para el que también se utiliza la escritura visigótica. ${ }^{17}$

Por último, Spannagel y Engelbert también sitúan dentro de la tradición hispánica el códice del British Museum (London), Add. 25491, 291 folios, escrito en pergamino a una columna, con una caja de escritura de $300 \mathrm{~mm} . \times 200 \mathrm{~mm}$., durante el siglo XIII. Quizás se trata de otro testimonio incompleto, ya que ni tan siquiera lo incluyen dentro del stemma que realizan de filiación entre los principales testimonios. Tampoco identifican su escritura, ni proponen lugar alguno de la península al que pudiera adjudicársele la copia.

Así pues, se nos han conservado copias más o menos fragmentarias de la obra de Smaragdo producidas en los más importantes scriptoria hispánicos medivales, sobre todo de origen castellano. ${ }^{18}$ La extensión de las copias es un nuevo indicio de que fue un texto básico y de gran repercusión dentro de los monasterios, con la finalidad de hacer más sencilla y comprensible la Regla benedictina, al menos, para el uso interno de las comunidades monásticas.

\section{EL MANUSCRITO LAT. 104 DE LA JOHN RYLANDS LIBRARY}

En la actualidad para establecer conclusiones sobre este códice es necesario partir del estudio que realiza B. A. Shailor comparando dicho testimonio con otros que, probablemente, compartan el monasterio de san Pedro de Cardeña como lugar de origen y el siglo $x$ como momento de creación. ${ }^{19}$ Un logro importante de este artículo es el de clarificar y corregir de manera definitiva una serie de errores referentes al manuscrito Lat. 104, que a pesar de estar señalados por investigadores anteriores, se seguían repitiendo en ocasiones. ${ }^{20}$ Pero, sin lugar a dudas, su gran aportación es el estudio que realiza desde la codicología y la paleografía de una serie de testimonios conservados con escritura visigótica, entre los que se encuentra nuestro Smaragdo.

17 Para una descripción pormenorizada y completa de dicho testimonio véase Cuenca, P. 2009: 85-88.

18 En el completo stemma incluido por Spannagel y Engelber en su edición crítica de Smaragdo. 1974: XLIII-XLVIII, establecen una serie de filiaciones a través de los errores por omisión cometidos en las diferentes familias textuales, a través del cual queda claro que todos los testimonios de origen hispánico están filiados entre sí ( $M, M n, S$ y Vv), pero ninguno de ellos tiene una procedencia directa de alguno de los testimonios conservados.

19 Shailor, B.A. 1978-79. "The scriptorium of san Pedro de Cardeña". Bulletin of the John Rylands Library 61, 1978: 444-473, compara seis testimonios llegando a la conclusión que deben datarse, sin lugar a dudas, en Cardeña durante la primera década del siglo x,: la Biblia de Cardeña (Archivo de la Catedral de Burgos), una copia de los Moralia de san Gregorio (Lat. MS. $83 \mathrm{JRL}$ ), la Smaragdi abatís Expositio in Regulam S. Benedicti, (Lat. MS. $104 \mathrm{JRL})$, De vita et miraculis patrum emeritensium (AHN, Sección de códices, carpeta 1452B, no9), las Etymologiae de san Isidoro (RAH, códice 25), el Codex Regularum (BL, add. Ms. 30.055) y Super Psalmos de Casiodoro (Lat. Ms. 89 JRL), único testimonio datado en el año 949 y, por lo tanto, posterior a los otros cinco.

20 Es el caso de la atribución de la copia al escriba Juan de Silos en el año 945 por parte de James, M. R. 1921. A descriptive Catalogue of the latin manuscripts in the John Rylands Library at Manchester, I: 185-7 Manchester: Manchester Univ. Press ( $n$ o 104), basando su atribución en Berganza (Antigüedades de España), lo cataloga como el ms. I del archivo de santo Domingo de Silos, a pesar de estar corregido este dato por otros autores, como señala Shailor B.A.. 1978-79: 455n. 


\section{Análisis codicológico.}

El manuscrito Lat. 104 de la John Rylands Library es un códice unitario que contiene de forma incompleta la Expositio in Regulam S. Benedicti que redactara el abad Smaragdo hacia el año $816 .^{21}$

Se trata de una copia de finales del siglo Ix o principios del siglo $x$ realizado en escritura visigótica redonda, sobre pergamino de baja calidad desgastado y blanquecino, especialmente por los bordes del códice, lo que ha llevado a la pérdida de algunos fragmentos de escritura que en la mayor parte de los casos ha sido restaurado en blanco. ${ }^{22} \mathrm{Al}$ mal estado de conservación hay que unir la mutilación en algunos folios de los márgenes izquierdo y superior, así como el enorme daño causado en el último cuaderno por las manchas de humedad y por otro tipo de manchas que parecen producidas por haber estado expuesto al fuego o al humo.

Contiene una modesta ornamentación consistente en el uso de los colores verde, rojo y amarillo en los títulos y dibujos de algunas letras mayúsculas ornamentadas (por ejemplo, véase el folio $55 r$ donde aparece la letra $M$ con forma de ángel), que se completa con el color negro utilizado para la copia del texto, como se puede comprobar en la siguiente imagen:

\section{IMAGEN 1a}

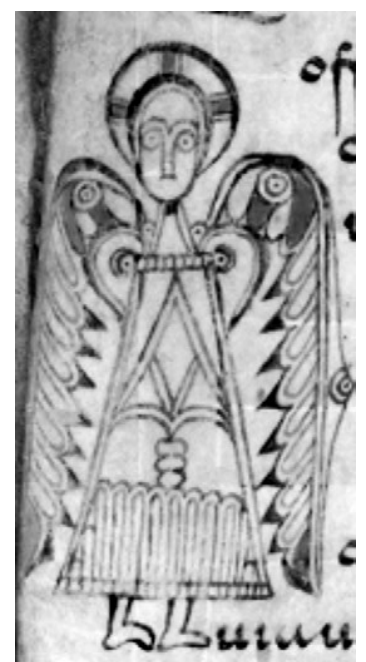

f. 55 r.
Las medidas del códice son $240 \mathrm{~mm} . \times 190 \mathrm{~mm}$. con una caja de escritura de $200 \mathrm{~mm} . \times 150 \mathrm{~mm}$, según tuve ocasión de comprobar en el propio manuscrito conservado en la John Rylands Library. ${ }^{23}$ Cada folio contiene 27 líneas escritas a línea tirada. En cuanto a la encuadernación, en un primer momento el códice tuvo hojas de guarda en pergamino que pertenecieron a algún texto de carácter musical, después le añadieron unas tapas de madera revestidas en cuero, que es la que posee en la actualidad.

Ocupa el códice un número total de folios de 188 $(1+186+1)$, aunque resulta difícil establecer una cantidad exacta. ${ }^{24} \mathrm{El}$ texto mantiene diferentes numeraciones incompletas y marcadas de forma irregular, así aparecen al menos dos numeraciones no coincidentes: una moderna en la esquina superior derecha y otra, que parece más antigua, en la esquina inferior derecha.

Además de las dos manos intervinientes en la copia del texto, aparecen anotaciones en escrituras diferentes como la visigótica cursiva, coetánea, y la humanística, utilizada para las glosas marginales.

La obra, que comienza de forma abrupta al faltarle el inicio, se divide en un prólogo que acaba en el folio $15 \mathrm{v}$ (Si autem eredes, sine dubio, et consorte erimus. Amen, deo gratias); a partir de este folio comienza el libro I, que finaliza en el folio $83 v$ (sicut fon uite promanet); el libro II finaliza en el folio 108v (quum exaltatione et gaudio. Amen, deo gratias). A continuación, en el folio 109r después del explicit del segundo libro aparece el incipit del tercero (Incipit liber tertius in beati Benedicti regula). El texto finalizará, también de forma incompleta, en el folio $185 v .^{25}$

\section{Análisis paleográfico.}

El manuscrito que lleva la signatura Ms. Lat. 104 de la John Rylands Library estuvo durante un tiempo atribuido por error al escriba Juan de Silos, al menos en su última parte, y datado en el año 945. Sin embargo, según los estudios críticos actuales, entre los que se encuentra la moderna edición del texto, dicho manuscrito se copió en una sede dependiente o en el propio monasterio de Cardeña a finales del siglo IX.

En el texto se puede identificar la intervención de dos manos diferentes que han copiado la mayor parte de la obra, con la inclusión de anotadores ocasionales, coetáneos en unos casos y muy posteriores en otros. Denominaremos, a partir de aquí, al amanuense que escribe del folio $1 r$ al folio

21 En la edición de Smaragdo.1974:xxix, Spannagel y Engelbert fijan este año como terminus post quem de la fecha de composición.

22 En cuanto a la datación del manuscrito Spannagel y Engelbert, en su edición de Smaragdo. 1974: XVII, sitúan el momento de la copia a finales del siglo IX, mientras que Shailor, B.A. 1978-79: 455 decide retrasar el momento de su composición a la primera década del siglo $\mathrm{X}$ : "I believe that the codex was produced in the scriptorium of Cardeña rather than in a dependent monastery, and that it can be firmly dated to the first decade of the tenth Century". James, M.R. 1921:185-187 lo fecha en el año 945 (in era 983); y Lowe, E. A. 1972. "Studia Palaeographica. A contribution to the history of early latin minuscule and to the dating of visigothic manuscripts", en L. Bieler (ed.), Palaeographical Papers, 1907-1965: 62n Oxford: Clarendon Press, donde propone la siguiente datación: "saec. IX ex ut videtur".
23 Tanto Shailor, B.A. 1978-79, como Spannagel y Engelbert en su edición de Smaragdo. 1974:xvii publican las medidas del códice, pero resulta curioso que siendo similares son todas diferentes. Si Shailor da las medidas $236 \mathrm{~mm}$. $\times 186 \mathrm{~mm}$. para el códice y $200 \mathrm{~mm} . \times 145 \mathrm{~mm}$. para la caja de escritura, Spannagel y Engelbert sólo ofrecen el dato de la medida total del códice, $252 \mathrm{~mm} . \times 190 \mathrm{~mm}$., seguramente siguiendo los datos de James, M.R. 1921: 185-187, quien tampoco incluye la medida de la caja de escritura en su catálogo (no 104).

24 En su edición de Smaragdo. 1974, XVI, Spannagel y Engelbert establecen una número de 185 folios sin mayor aclaración.

25 Se añade al final del presente artículo una ficha codicológica completa del ejemplar. 
19r copista número 1 , dejando la denominación de copista número 2 para el que realiza el resto del manuscrito. ${ }^{26}$

Desde el punto de vista paleográfico y basándonos en la distribución que establece el propio texto, vamos a intentar describir, a través del análisis de las diferencias gráficas, los usos que de la escritura visigótica se realizan en este códice en el scriptorium de Cardeña a finales del siglo IX o principios del $x .{ }^{27}$ Existen, no obstante, una serie de características generales comunes, atribuibles seguramente a una formación similar, que son coincidentes en ambos copistas, como el caso del irregular modo de separar las palabras o la falta de interés por mantener de forma precisa el apoyo de las letras en la línea de renglón.

El siguiente análisis, para el que tengo muy en cuenta el realizado por Shailor en su excelente artículo tantas veces aquí citado, se centra en las diferentes características gráficas de los dos copistas que intervienen de forma mayoritaria en el manuscrito, ya que la investigación va dirigida a justificar la existencia de ambas manos basándonos en las posibles diferencias deducidas del riguroso examen paleográfico de las mismas. En este caso, por tanto, el objetivo principal no es llegar a poder filiar las formas gráficas, sino tan sólo diferenciarlas para establecer de forma definitiva la doble intervención de copistas en el códice.

\section{Diferencias:}

En el cuadro propuesto al establecer las características gráficas más importantes de los diferentes manuscritos que estudia en su trabajo, Shailor distingue entre los dos copistas que intervienen en la copia del manuscrito Rylands, Latin. Ms. 104, basándose en tres cuestiones gráficas que se producen de forma distinta en cada uno de ellos: ${ }^{28}$

El uso de marcas textuales en el copista 1, frente a su ausencia en el otro copista.

La forma de abreviar la sílaba "per", ya que el primer copista corta el caído hacia fuera y el segundo realiza el corta girando hacia el propio caído.

La abreviatura de las expresión latina "id est", representada por el primer escriba como una "i" alta seguida de una " $d$ " con el astil cortado por el signo abreviativo general, frente al segundo que además añade al final una " $\mathrm{t}$ " de tipo uncial.

A las características mencionadas por Shailor, cabría añadir otras que, desde el punto de vista paleográfico, pueden reforzar la división propuesta en cuanto a las dos manos intervinientes en la copia del texto, como son las tres características gráficas que analizamos a continuación ilustrándolas con las imágenes correspondientes del manuscrito:

26 La intervención de estas dos manos ya fue detectada por Shailor, a quien debemos esta distribución concreta, localizando en el folio 19r la división del trabajo. Aunque resulta indudable la presencia de dos copistas, parece aventurado certificar una división tan exacta debido a la gran similitud de ambas escrituras.

27 En su edición de Smaragdo. 1974: XVII, Spannagel y Engelbert datan el testimonio a finales del siglo IX mientras que Shailor lo sitúa a principios del siglo $x$.

28 Shailor, B.A. 1978-79: 29.
El ángulo de inclinación también cambia entre los dos amanuenses. El primero mantiene una escritura vertical, mientras que el segundo muestra una clara inclinación hacia la izquierda, marcada sobre todo en los astiles de "i" alta y "I". Ahora bien, utilizando este mismo criterio, es bastante posible que las anotaciones marginales (por ejemplo, de los folios $172 v$ y $173 r$ ) correspondientes en la división de Shailor al segundo copista, sin embargo, hayan sido realizas por el primer copista o bien por un tercero, puesto que la verticalidad vuelve a ser absoluta, como se puede comprobar comparando las dos imágenes siguientes:

\section{IMAGEN 2a}

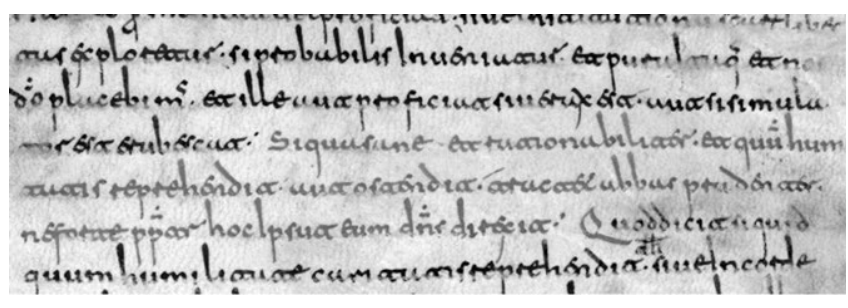

JRL, Lat. Ms. 104, parte central del folio 172v. Copista número 2

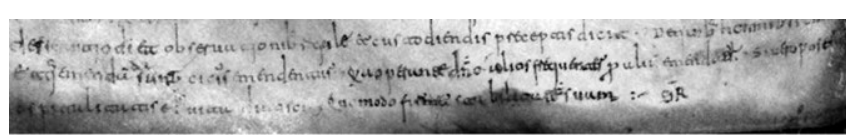

Anotación en el margen inferior del mismo folio. Copistas 1 o 3.

Existe otra característica gráfica cuya realización se detecta sólo en los folios pertenecientes al primer copista, en teoría, si bien tampoco aparece en los folios iniciales donde se contiene la tabla de los capítulos (folios 15v a 16v). Me refiero a la conversión de la "i" corta en larga en todos los casos en que aparece formando parte del grupo "ti". Por ejemplo, reproducimos a continuación en la cuarta imagen un fragmento del folio $18 \mathrm{v}$, donde nos encontramos en doce líneas siete casos del mismo uso:

\section{IMAGEN 4a}

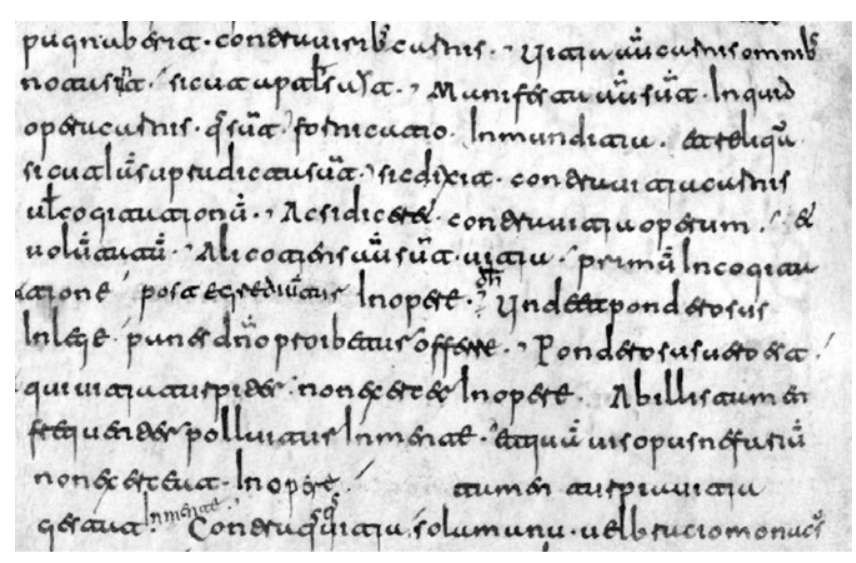


Los alargamientos de la letra "i" se producen con un trazo claramente añadido, mediante una extensión similar en todos ellos y usando el instrumento escriptorio de modo que su trazado queda con menor intensidad y grosor que el del resto de la escritura, lo que podría sugerir incluso otro momento de copia diferente al del resto del texto. El hecho de que aparezca siempre el alargamiento de la vocal en el grupo "ti" podría tomarse como uno de los elementos de datación de la escritura visigótica que señalara Lowe y que con posterioridad, tan útiles han sido para los paleógrafos modernos. ${ }^{29}$ El propio investigador, sin embargo, cita el presente códice como uno de los que no presenta diferencias gráficas en la realización de dicho grupo dependiendo de si se trata de un sonido fuerte o suave: "29. Manchester John Rylands Library MS. Lat. 104 (116). saec. IX ex. [...] (a) No ti-distinction: "Iustitia", "mentis", "cogitatione". ${ }^{30}$ Por lo que se refiere al aspecto gráfico, en todos los casos observados el grupo "ti" se compone de una " $\mathrm{t}$ " uncial seguida de una "i" corta, convertida en larga por el trazo añadido. No se encuentra ningún caso en que dicho grupo gráfico se realice con una morfología de beta invertida, dependiendo de su grado de asimilación.

En la escritura mayúscula, hay otra característica gráfica que muestra de nuevo dos formas diferentes de llevar a cabo grafías muy similares, si dejamos a un lado ahora el concepto de ductus que, como explicara Jean Mallon, no sirve para diferenciar manos puesto que es un rasgo imitable y artificial de la escritura en tanto que proviene del aprendizaje. Nos referimos a la realización de la letra mayúscula "N", ya que dicha letra aparece en ambos casos utilizada en similares condiciones textuales después de un signo de puntuación fuerte, como se puede observar en las dos imágenes reproducidas a continuación: en un caso, utiliza el copista el punto y la coma; en el otro, los dos puntos según aparecen en la segunda línea de la caja de escritura en el margen izquierdo:

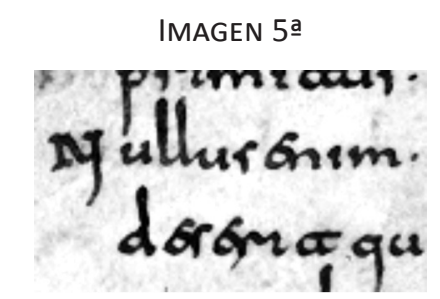

f. $18 \mathrm{v}$, copista 1

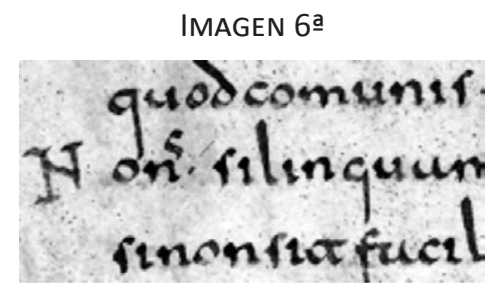

f. $108 \mathrm{v}$, copista 2

29 Lowe, E.A. 1972: 37: "The distinction between assibilated and unassibilated ti was in time graphically represented. As this question is of importance in dating Visigothic manuscripts, it has been treated separately and at greater length below".

30 Lowe, E.A. 1972: 48.
Son dos formas claramente diferenciadas de realizar los trazos gráficos que componen la letra. Mientras que el primer copista opta por la ornamentación y el dibujo, el segundo esquematiza todos y cada uno de los golpes de pluma que conlleva esta letra en el alfabeto visigótico, sin obviar los trazos horizontales que rematan los verticales y oblicuos. En la misma dirección del caso anterior, apuntan los siguientes ejemplos reproducidos en la imagen séptima y en la octava. Ambos copistas construyen una frase similar en morfología mayúscula:

IMAGEN 7모

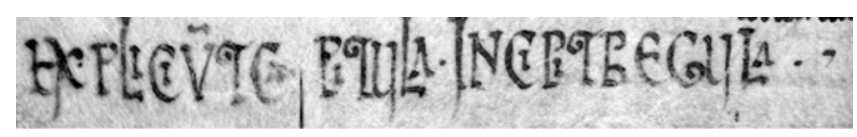

Fol. 16v. Copista 1

IMAGEN 8aㅗ

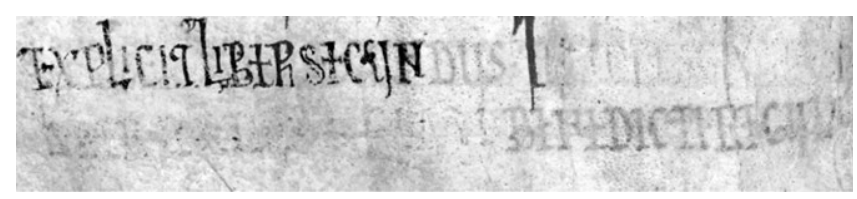

Fol. 108v. Copista 2

Parece indiscutible que en ambos casos se parte de morfologías habituales dentro de los alfabetos visigóticos redondos o sentados, pero el estilo de cada copista es diferente. Si el primer copista tiende al trazo redondeado (así en las letras " $C$ " $\mathrm{Y}$ " $E$ "), al uso de la letra "I" incluida en otras (es el caso "LI", "Cl" y "PI") y a la verticalidad en el ángulo de inclinación del astil de la letra " $\mathrm{L}$ ", el segundo basa su trazo en las líneas angulosas, no siempre recurre a la letra "I" incluida (véase "BENEDICTI") y, de nuevo, como ocurriera en la escritura minúscula muestra una clara inclinación hacia la izquierda al realizar los astiles de la letra "L".

Por último, aunque son numerosos los motivos que desde el punto de vista paleográfico nos llevan a pensar en, al menos, dos copistas diferentes como propuso Shailor, hay que tener en cuenta la complejidad de los códices visigóticos y su riqueza, que va mucho más allá de lo que se puede exponer en trabajos parciales. Con esta contribución, he querido explicar algunos aspectos relevantes de la escritura del códice que pueden contribuir al mejor conocimiento de su análisis definitivo o completo. Para muestra de la mencionada complejidad, me gustaría finalizar proponiendo la siguiente reflexión. Si los dos copistas escriben en escritura visigótica redonda o sentada, ¿quién escribe la frase en escritura visigótica cursiva reproducida en la última imagen?

\section{IMAGEN 9a}

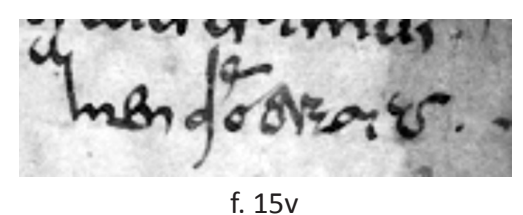

Hispania Sacra, LXVIII

137, enero-junio 2016, 179-186, ISSN: 0018-215X, doi: 10.3989/hs.2016.012 
La pregunta anterior es sólo una de las múltiples cuestiones que puede suscitar todavía el análisis pormenorizado y riguroso de las manos que intervienen en la copia de este tipo de códices. En muchos casos, su escritura era compartida por unos copistas que realizaban la mayor parte del texto, como los dos que hemos caracterizado en el presente estudio. Sin embargo, el análisis paleográfico detecta que hubo otros copistas ocasionales que, de forma más esporádica, dejaron también su huella en la escritura.

FICHA CODICOLÓGICA DEL MS. LAT. 104 DE LA JOHN RYLANDS LIBRARY

1.- Identificación.

- Lugar de depósito: Manchester (England).

- Nombre de la institución: John Rylands Library.

- Signatura: Lat. 104 (116).

- Autor: Smaragdo.

- Título uniforme: In regulam santi Benedecti.

- Título facticio: Commentarii in regulam sancti Benedicti.

- Datación: siglos IX-X.

- Soporte: pergamino.

- Dimensiones: códice 240mm.×190.5mm.

- Número de folios: I+188+I.

2.- Composición material.

- Análisis del soporte: Pergamino de animal joven y de calidad media-baja por su espesor y color. Bien trabajado en el proceso de elaboración, sin apenas marcas del proceso de depilado y muy satinado.

- Tipo de composición: unitario.

- Tipología de los cuadernos: cuaterniones (el cambio de mano se produce en la mitad del tercer cuaderno). El último cuaderno con humedad y muy ennegrecido.

- Anomalías: Mal conservado, contiene mutilaciones en los márgenes y constantes manchas de humedad en la parte superior, sobre todo en el último cuaderno.

3.- Composición de la página.

- Dimensión del folio: $240 \mathrm{~mm} . \times 190.5 \mathrm{~mm}$.

- Caja de escritura: $200 \mathrm{~mm} . \times 150 \mathrm{~mm}$.

- Disposición de la escritura: línea tirada.

- Líneas por folio: 27.- Diseño del pautado: consta de una doble línea tanto en el margen como en el justificado, que sirven para enmarcar la caja de escritura, pero no se respetan con mucha precisión. No se aprecian líneas rectrices ni de escritura.

- Numeración de los folios: aparecen tres numeraciones diferentes, no siempre conservadas:

a) En romanos, en color rojo y situada en el centro inferior del folio.

b) En arábigos, doble numeración que no coincide:

b.1. En el margen superior derecho.

b.2. En el margen inferior derecho.

\section{Encuadernación}

Encuadernado en madera revestida de cuero, se utilizan folios de pergamino de un códice musical para el interior, quizás resto de una primera encuadernación.

\section{BIBLIOGRAFÍA}

Canellas, A. 1980. "Los escritorios benedictinos". Cuadernos de historia Jerónimo Zurita 37-38: 163-173.

Cuenca, P. 2009. "Un fragmento de un códice visigótico en la Biblioteca Nacional (ms. 18672)" en J.C. Galende y J. de Santiago (dirs.), VIII Jornadas Científicas sobre documentación de la Hispania altomedieval (ss. VI-X): 79-88, Madrid: Departamento de Ciencias y Técnicas Historiográficas/ Universidad Complutense de Madrid.

James, M. R. 1921. A descriptive Catalogue of the latin manuscripts in the John Rylands Library at Manchester, I Manchester: Manchester Univ. Press.

La Corte, D. H. 2006. "Smaragdus of Saint-Mihiel: NinthCentury Sources for Twelfth-Century Reformers". Cistercian Studies Quaterly, 41: 273-290.

Leclercq, J. 1957 (reed. 1982), The Love of learning and the Desire for God: A study of Monastic Culture: 45-47 New York, Fordham University Press.

Leclercq, J. 1984. "Smaragdus", en P. E. Szurrmach (ed.). An Introduction to the Medieval Mystics of Europe: 37-39, Albany: State University of New York Press.

Linage Conde, A. 1976. "Un testimonio de la europeización riojana en el siglo X". Biblioteca Gonzalo de Berceo: 85-105 (www.vallenajerilla.com).

Lowe, E. A. 1972. "Studia Palaeographica. A contribution to the history of early latin minuscule and to the dating of visigothic manuscripts", en L. Bieler (ed.), Palaeographical Papers, 1907-1965: 2-65 Oxford: Clarendon Press.

Ponesse, Matthew D. 2006. "Smaragdus of St. Mihiel and the Carolingian Monastic Reform". Revue Bénédictine 116: 367-392.

Ruiz, Ë. 1997. Catálogo de la sección de Códices de la Real Academia de la Historia: 201-203 Madrid: Real Academia de la Historia.

Shailor, B.A. 1978-79. "The scriptorium of san Pedro de Cardeña". Bulletin of the John Rylands Library 61: 444-473.

Smaragdo. 1974, Expositio in Regulam S. Benedicti A. Spannagel y P. Engelbert (eds.) Siegburg (Alemania): Franz Schmitt.

Smaragdo. 2007. Commentary on the Rule of Saint Benedict D. Barry (trad.) Kalamazoo: CistercianPublications.

Traube, L. 1988. "Textgeschichte der Regula S. Benedicti, Bayerische Adademie der Wissenschaften München". Abhandlungen der Philosophisch (-philologischen)- historischen klasse 21/3:, 646-7 y 717-8. 